\title{
The outcomes of stress exposure in hemodialysis patients
}

\author{
Mahin Naderifar ${ }^{1}$, Mansoureh Zagheri Tafreshi ${ }^{2 *}$, Mahnaz Ilkhani ${ }^{3}$, Amir Kavousi ${ }^{4}$ \\ ${ }^{1}$ School of Nursing and Midwifery, Shahid Beheshti University of Medical Sciences, Tehran, Iran \\ ${ }^{2}$ Department of Nursing Management, School of Nursing and Midwifery, Shahid Beheshti University of Medical Sciences, Tehran, Iran \\ ${ }^{3}$ Department of Medical-Surgical Nursing, School of Nursing and Midwifery, Shahid Beheshti University of Medical Sciences, Tehran, Iran \\ ${ }^{4}$ Department of Health, Safety and Environment, School of Health, Safety and Environment, Shahid Beheshti University of Medical \\ Sciences, Tehran, Iran
}

\section{A R T I CLE IN F O}

Article Type:

Original

\section{Article History:}

Received: 3 March 2017

Accepted: 29 June 2017

Published online: 23 June 2017

\section{Keywords:}

Stress exposure

Outcomes

Hemodialysis

Qualitative research

\begin{abstract}
A B S T RA C T
Introduction: Chronic renal failure (CRF) is a common problem in today's world. Patients with hemodialysis are subjected to stress even more severe than others.

Objectives: This study aimed to explain patients' perception with hemodialysis about stress exposure and its consequences.

Patients and Methods: This study is a qualitative approach based on directed content analysis. The data were collected using semi-structured in-depth interviews with patients treated with hemodialysis. Participants were selected using purposive sampling method and data saturation was reached by conducting 11 interviews so that, the new finding was not added. Data analysis was simultaneously conducted based on Grant's model of the consequence of exposure to stress. The validity and reliability of the data was confirmed using peer review method and results were also confirmed by participants.

Results: Four themes, including support, psychological outcomes, adherence to treatment and physical trouble, 12 categories and 33 sub-categories were obtained during data analysis process. According to the results, "support" was added.

Conclusion: The results showed that patients, with the help of available supportive resources, confront with the difficulties that lie ahead and reduce the hemodialysis-related stress in themselves. Support resources including; family, medical personnel, similar patients, friends and community resources.
\end{abstract}

Implication for health policy/practice/research/medical education:

Nurses and policy makers should have special attention to consequences of stress in patients undergoing hemodialysis. It plays an important role to provide a framework for appropriate supportive measures and gives the opportunity for nurses to manage the problems facing these patients.

Please cite this paper as: Naderifar M, Zagheri Tafreshi M, Ilkhani M, Kavousi A. The outcomes of stress exposure in hemodialysis patients. J Renal Inj Prev. 2017;6(4):275-281. DOI: 10.15171/jrip.2017.52.

\section{Introduction}

Chronic renal failure $(\mathrm{CRF})$ is a common problem in today's world. End-stage renal failure (ESRD) is one of the major health problems in kidney patients (1). The incidence of ESRD increased from 238 cases in 2000 to 357 cases per 1 million people in 2006 in Iran (2). Hemodialysis is the common treatment for ESRD. Hemodialysis causes changes in individuals' lifestyle, health status and roles. These patients face with multiple physical, mental and social stressors (3).

Patients treated with hemodialysis experience restrictions on lifestyle, diet and fluids (4). Hemodialysis patients should follow strict diet, fluid restriction and special food and medication. In addition, there are numerous hemodialysis-related physical, mental and social health problems, which make it difficult to accept this type of treatment (5).

Although hemodialysis cannot treat the disease and compensate for all endocrine or metabolic functions of the kidneys, it is associated with acute complications such as hypotension or muscle cramps, anemia or viral hepatitis (6). In addition, patients often feel a lack of 
freedom, attachment to caregivers, family life and social disorder, decreased or lack of income (7). Fatigue, lethargy, impotence, decreased libido and even severe depression along with time-consuming and intolerable dialysis can reduce sense of wellbeing in the patients (8) and change quality of their life (7).

Today, it is recognized that people use different coping responses while confronting with stressful situations. Using a variety of methods to deal with stress is associated with different consequences on physical and mental health of individuals. Coping skills are passive or active efforts used in response to threatening conditions and to reduce emotional discomfort (9).

According to the conceptual model of the stress outcome exposure, if situations are understood as stressful, the individual will applies coping mechanisms into three response groups, including behavioral, physiological and psychological mechanisms in order to adapt to environmental needs (10).

Physiological mechanisms affect the autonomic nervous system and the immune, digestive, nervous-muscular and cardiovascular systems, which lead to adaptive physiological changes characterized in the form of physical symptoms, such as rapid heart rate, increased sweating and increased gastrointestinal motility (11). Behavioral responses to stress can increase the risk of disease. While confronting with stressful situations, people are likely to show health-endangering behaviors, such as changes in eating and sleeping habits, alcohol consumption, lack of adherence to treatment and changes in quality of life (12). Psychological mechanisms increase risk of the mental injury. For example, one's thinking patterns are changed and they have a feeling of depression and anxiety, or one's perception of his/her disease is increased and consequently, the need for medical interventions is increased (11).

Exploring the perceptions of patients undergoing hemodialysis leads to better understanding of the meaning of stress exposure outcome. It also helps the medical team especially nurses to find ways leading to understanding patients' needs as well as improvement of care services. Further, this explanation encourage nurses apply more effective and supportive strategies to patients by identifying factors affecting this experience at individual, family and organizational levels.

\section{Objectives}

This qualitative research aimed to identify stress exposure outcomes in patients undergoing hemodialysis in order to test and develop the Grant's model. Directed content analysis is one of the qualitative approaches to identify and describe the dimensions of a phenomenon based on a conceptual model (13). It allows researchers to interpret the authenticity and truth of data in a subjective but scientific method way and provide knowledge of relevant experience with the identified concept in the sociocultural context of the country $(14,15)$.

\section{Patients and Methods}

Study protocol

Considering that Grant's conceptual model of stress exposure outcomes, directed content analysis method was used to identify the model's aspects in the context of research and its development (13). This study was conducted from May to November 2015. Eleven patients with hemodialysis who referred to five hospitals affiliated to Shahid-Beheshti University of Medical Sciences in Tehran were selected using the purposive sampling method. Participants with ESRD who were undergoing hemodialysis from one week to one year participated with written informed consent. Exclusion criteria included hearing or speech difficulties and reluctance to participate in the study. Sampling was carried out after obtaining the ethical approval code from Shahid-Beheshti University of Medical Sciences and coordination with hospitals officials. Participants were assured that all their personal information will remain confidential at the time of publication of the results.

\section{Ethical issues}

1) The research followed the tenets of the Declaration of Helsinki and its later amendments; 2) informed consent was obtained; and 3) Permission of the ethical review committee of Shahid-Beheshti University of medical sciences was obtained prior to execution of the study.

\section{Data collection and analysis}

The main method of data collection included semistructured in-depth interviews based on the objectives of the study. Each interview lasted for 30 to 90 minutes (mean $=50$ minutes) until participants believed that they have no more to say. Interviews were conducted in dialysis or nephrology wards considering the patient's comfort and privacy about the place and time. The interviews were recorded and were typed verbatim in the shortest possible time after each interview. The texts were entered into MAXQDA software for data management purposes. All interviews comprised the analysis unit, which was analyzed several times after typing. The semantic units were later marked in the form of sentences or paragraphs from the statement and interview texts and initial codes were later extracted. The relevant codes were compared regularly by continuous comparative analysis process and according to the Grants' model variables, the subcategories and main categories were gradually formed and themes were obtained (13). To increase the rigor of data, long-term involvement with the subject, findings confirmation by the participants (member check) in the case of any ambiguity in the extracted codes and also observers' revision had been considered to investigate the codes and categories extraction process (peer check) (16).

\section{Results}

Participants included 11 patients (Table 1), 6 women and 5 men aged 32-63 years (mean $=54.2$ years), who were undergoing dialysis three times a week for 4 hours 
Table 1. Demographic characteristics of participants

\begin{tabular}{|c|c|c|c|c|c|}
\hline Participants & Sex and age (years) & Marital status & Level of education & Employment status & Duration of hemodialysis (months) \\
\hline 1 & $F / 32$ & Single & Bachelor & Employed (office) & 11 \\
\hline 2 & $\mathrm{M} / 43$ & Married & Diploma & Self-employed & 8.5 \\
\hline 3 & $F / 58$ & Married & Illiterate & Housewife & 6.5 \\
\hline 4 & $M / 48$ & Married & Diploma & Employed (driver) & 9.5 \\
\hline 5 & $M / 63$ & Married & Fifth grader & Retired & 8.5 \\
\hline 6 & $\mathrm{~F} / 62$ & Married & Fifth grader & Housewife & 6.5 \\
\hline 7 & $\mathrm{~F} / 59$ & Married & Illiterate & Housewife & 7.5 \\
\hline 8 & $\mathrm{~F} / 52$ & Married & Fifth grader & Housewife & 6.5 \\
\hline 9 & $F / 36$ & Married & Diploma & Housewife & 1 \\
\hline 10 & $M / 50$ & Married & Guidance & Retired & 9 \\
\hline 11 & M / 39 & Married & Diploma & Self-employed & 10.5 \\
\hline
\end{tabular}

(only one participant for 3 hours). There were various participants in terms of marital status, level of education and employment status. History of dialysis ranged from 1 to 12 months (mean $=7.7$ months).

At the end of the data analysis, a total 886 initial codes were obtained that were placed in 47 primary sub-categories. After ongoing review of extracted codes, removing and merging duplicates codes and categories, a total of 33 subcategories in 12 main categories were extracted and four themes were obtained including "support", "psychological consequences", "adherence to treatment" and "physical trouble" (Table 2).

\section{Support theme}

Patients stated that supportive resources will help them to confront with the difficulties ahead successfully and reduce the stress caused by exposure to hemodialysis. The use of supportive resources plays an important role in helping patients to return to normal and active life. The patients' experiences show that satisfaction with supportive resources (including family, medical personnel, similar patients, friends and social resources) makes them feel comfortable and accelerates their return to normal life, while the lack of these supportive resources leads to insecurity and stress in patients. This theme includes three main categories as "family support", "peers support" and "social support".

\section{Family support}

This category consists of "patient's family supports", "family support of patient's spouse", "poor family support" and "spousal support". A participant expresses his feeling about the role of family support as follows:

"I sometimes think even my family, forgets what problem I have. I do not know whether it is due to social problems or something else ..., however, I feel sometimes I am really forgotten." (Male, 48 years old)

\section{Peer support}

It includes patients and friends support. A 43-year-old patient says about the role of peers and being with people who have the same problem:

"Having a friend is very effective... there was a patient who never talk to any one even the nurse, it is very hard... we need to unburden ourselves to other patients."

\section{Social support}

It includes subcategories of specific medical insurance, nurses/physicians support, and governmental/nongovernmental support. One of the participants said about the role of medical staff in his stress reduction:

"These nurses also gave us spirit and said that it is great you can treat by hemodialysis, there are some patients whose conditions are worse than you and cannot be cured. You are at least undergoing the treatment process and there is no

Table 2. Themes, main and sub-categories of data analysis

\begin{tabular}{|c|c|c|}
\hline Themes & Categories & Sub-categories \\
\hline \multirow{3}{*}{ Support } & Family support & Patient's family support, Family support from the patient's spouse, Poor family support, Spousal support \\
\hline & Peers support & Supports from friends or other patients \\
\hline & Social support & Special insurance protection, nurses/physicians (medical staff) support, GO/NGO's support \\
\hline \multirow{4}{*}{$\begin{array}{l}\text { Psychological } \\
\text { consequences }\end{array}$} & Concern/Worry & Shock of disease, fear of death, fear of disease, fear of medical procedures, uncertain future \\
\hline & Denial & Denial, secrecy, disbelief \\
\hline & Anxiety & Aggression, stigmatization, distress, isolation \\
\hline & Depression & Pessimism and negative thinking, feeling of helplessness \\
\hline \multirow{3}{*}{$\begin{array}{l}\text { Adherence to } \\
\text { treatment }\end{array}$} & Diet acceptance & Restriction of food intake and strict diet \\
\hline & Disease acceptance & Information search, need to mental preparation \\
\hline & Treatment acceptance & Forced choice and obligation to be treated \\
\hline \multirow[b]{2}{*}{ Physical trouble } & Clinical problem & Disturbance in physiological indices, complications of diseases \\
\hline & $\begin{array}{l}\text { Disturbance in activity } \\
\text { daily living ( } A D L)\end{array}$ & Movement disorders, treatment complications \\
\hline
\end{tabular}


problem, don't worry at all." (Male, 39 years old)

\section{Psychological consequences theme}

It includes four categories as concern/worry, denial, anxiety and depression. There is a risk of psychological problems and depression in chronic diseases that associated with hopelessness, sadness, lack of motivation, loss of confidence and pessimism. Researches have shown that if environmental stressors remain for a long time, they will lead to physical and psychological problems.

\section{Concern/worry}

It includes shock of disease, fear of death, fear of disease, fear of medical procedures and uncertain future. A 52-year-old female patient stated about her shock of facing dialysis treatment at first time:

"I am so stressful, perhaps you may not believe... sometimes when I sleep and wake up, I think all is just nightmare, I cannot believe it ..., I feel stress the night before I want to go for the dialysis."

Also, another participant stated about uncertain future: "However, we're undergoing dialysis and it is unclear what's our future is. I'm not healthy. I feel very sick. I fear the future; this means that, for example, I really think how long the dialysis can help me stay on my feet." (Female, 59 years old).

\section{Denial}

It includes denial, secrecy and disbelief. A participant expressed about the denial of his disease:

"I didn't accept that I should undergo dialysis at all....my condition was too deteriorated to the extent that I was forced to undergo the dialysis and I didn't accept that I must refer for the dialysis treatment". (Male, 39 years old)

\section{Anxiety}

It includes of aggression, stigmatization, disease-related stress and isolation. One of the participants said about aggression and his wife's role in calming his anxiety:

"If, for example, I show aggression and talk with her aggressively... well, I cannot control myself... I have diabetes too...sometimes I forget something ... but she speaks very calmly with me and says that it is not good for your health to be aggressive, she tries to calm me down." (Male, 50 years old).

\section{Depression}

It includes pessimism and negative thinking and feeling of helplessness. A 59-year-old female patient said about her negative feeling at early exposure to dialysis:

"I had very bad feeling the first two or three months... perhaps my mind was a bit negative and sad...where is here?... why do I always feel bad?... the thought that I must go for dialysis makes me sad the night before."

\section{Adherence to treatment theme}

It consists of three categories including diet acceptance, disease acceptance and the obligation to treat. Adherence to diet and fluid intake restriction help patients achieve optimal health outcomes. Increasing the intake of improper foods and drinks increases the likelihood of production of metabolites in blood and fluid poisoning and leads to premature mortality.

\section{Diet acceptance}

Restrictions on the use of food intake and strict adherence to diet are its subcategories. In this regard, one participant stated:

"This diet makes the patient unable to cope with his/her disease..., because the patients become annoyed, why I shouldn't drink water, why I shouldn't eat special food, why I shouldn't eat this or that ... what is this disease?" (Male, 50 years old)

\section{Disease acceptance}

It includes two subclasses of information search and need to mental preparation. A 32-year-old woman who was looking to raise her knowledge about the disease and reduce the dialysis stress exposure said:

"...The information acquisition was very useful for us because the fact of hemodialysis process and we are patients with hemodialysis... I think it is our duty to find information about it and its process... we must have information."

\section{Forced treatment}

It consists of two subcategories of forced choice and obligation to be treated. In this regard, one participant stated:

"I must undergo hemodialysis, if I don't accept this artificial kidney and not obey this process, I have no other choice, this artificial dialysis is the only solution." (man, 63 years old)

\section{Physical trouble theme}

It consists of two categories including clinical problems and disturbance in activity daily living. Hemodialysis accelerates other chronic diseases such as diabetes, high blood pressure, etc. Taking medication to treat the underlying disease, repeated visits to physicians and medical centers, side effects of the underlying disease on the kidney and its treatment are challenging for patients' health status.

For example, hemodialysis in patients with CRF requires access to adequate blood circulation. Vein arteriovenous fistula is the best method to achieve good blood circulation for long-term hemodialysis. Arterial venous fistula is possible if the patient has a suitable blood vessel. The risk of some chronic diseases, especially diabetes and atherosclerosis create a lot of vascular problems in patients and thus creating problem for vein arteriovenous fistula for hemodialysis access to the circulation.

\section{Clinical problems}

It includes disturbance in physiological indices and complications of underlying diseases. A female patient (59 years old) said about the hemodialysis stress and its complications in diabetic patients; 
"The condition of patients with diabetes and hypertension is the worst of all; this is the experience I found here; especially diabetes, because it has troubles internally. High blood sugar affects the whole body, so, they face e a bit worse condition than others."

\section{Disturbance in activity daily living}

Movement disorders and treatment complications are two subcategories in this issue. One participant described the treatment of complications of hemodialysis procedures; "The needle was inserted twice and they saw no blood entering into it ..., the personnel took out the needle and inserted another needle, but again no blood enters the syringe. They tried the third and the same problem insisted. These problems make me sad." (Female, 36 years old) In the present study, the stress outcome exposure model variables included demographic characteristics, behavioral, physiological and psychological responses. In addition, "support" as a new emerged variable was raised in the qualitative results and the participants referred to the significant role of them in their confrontation with hemodialysis stress exposure and its consequences.

\section{Discussion}

The present study aimed to explain the viewpoint patients treated with hemodialysis in the face of stress and its consequences. The results of this study showed that the consequences of stress based on the Grant's model include four themes as "support", "psychological consequences", "adherence to treatment" and "physical trouble". Accordingly, the "support" theme was added to the Grant's model of stress consequence exposure. In line with the present study, Vazquez et al stated that the family, staffs and managers have a central role in providing social support in patients with chronic diseases, including CRF undergoing hemodialysis. The consequences of the disease increase the need to wide range of supports in patients. The support can be provided in the form of psychological, emotional, informational, tangible and sociable support (17). In fact, reducing their tension in patients requires identification of the sources of social support in these patients. In this study the family support was one of the extracted categories. Most participants expressed that they had feeling of being supported because of the family attention and support. Since hemodialysis patients spend a large part of their time with their family, the family support is one of the main sources of support available to them (18). The results of another study also confirm other the findings of the present study, suggesting the family is the most effective support of patients in various aspects of their life (19).

Patients look at physicians and nurses as sources of social support, especially in terms of education and manner of treatment. In this regard, Molazem et al reported that when the nurse attends beside the patients, they feel nurse's vigilant eyes are always watching them and he/ she is always close to them, which is related to pleasant comfortable feeling and peace of mind in them (20).
In this study, it became clear that psychological outcomes, consistent with the Grant's (11) views, are among major consequences of stress exposure. Concern, denial, anxiety and depression are the categories obtained in this study. Welch and Austin stated that depression and anxiety are the most important reactions in patients with CRF, which affect their survival life span (21). Many researches confirmed the high prevalence rate of depression in patients with $\mathrm{CRF}$ as the most common psychiatric diagnoses due to many social problems or mental stresses, which are associated with high rates of morbidity and mortality. Joshwa et al stated that the depression prevalence among these patients is $72 \%$ in India, $12 \%$ of whom suffer from severe depression (22) and in Iran the prevalence is $79 \%$ (23). Depression symptoms in chronic dialysis patients are more prevalent than other chronic diseases. Most of the studies noted that depression and then anxiety are the most common symptoms of mental illness in the dialysis patients (24). In a study on Brazilian dialysis patients, the depression prevalence rated about 33\%-55\%, which there was a relationship between depression and mortality in these patients (25).

Adherence to treatment is another concept that was emphasized in Grant's conceptual model of stress exposure as a behavioral response. Adherence to treatment means the adherence to diet, fluids and medications prescribed by health care providers have a significant effect on the health and well-being of patients undergoing hemodialysis and help them to achieve optimal health outcomes (26). The non-adherence to treatment is reported as a common issue in patients with CRF, which is associated with the increased speed of disease progression and mortality (27). The failure of these patients to adhere to prescribed treatments (dietary restrictions and fluid intake) is one of the most important health care issues (28).

Adherence to restricted fluid intake is considered as the most difficult stressors in patients undergoing hemodialysis. Increasing the intake of improper foods and drinks increases the likelihood of production of metabolites in blood and fluid poisoning and thus creating complications and premature mortality (29). Kara et al found that $58 \%$ and $68.1 \%$ of patients had mild to very severe non-adherence to diet and mild to very severe fluid intake, respectively (30). In another study, the diet and fluids non-adherence rates were reported $25.1 \%$ and $18.4 \%$ in dialysis patients, respectively (31). The difference in results on the lack of adherence to treatment can be justified considering the economic situation and deprivation and living conditions of people in the region as well as the relevant costs such as commuting for hemodialysis, inability to work effectively, associated diseases as well as the use of different methods to assess patients' adherence in different studies. These patients need dietary changes, including protein intake, attention to the fluid intake proportional to waste fluids, sodium intake proportional to excreted sodium and restriction on consumption, potassium, consumption of enough calories and vitamin supplements (32). 
The last theme extracted in this study was the physical trouble. Hemodialysis treatment, is along with side effects such as hypotension, muscle cramps, nausea and vomiting, headache, chest pain, itching and dry skin. These side effects expose patients to some long-term complications, which is also known as uremic syndrome and include motor neuropathy, myopathy of skeletal or cardiac muscles, vascular periphery changes, increased the resistance of blood vessels, anemia, loss of erythropoietin productions, inefficient bone metabolism, various physical complaints, anesthesia, fatigue, depression and anxiety (33). These patients have difficulty in physical functions, such as climbing stairs, walking, lifting heavy objects and so on. Both nature of the disease and the type of treatment involve side effects such as cardiovascular diseases, metabolic disorders etc. So, it is not far-fetched that role limitations are more seen in this group of patients due to physical problems and pain (34), and the majority of hemodialysis patients has inactive lifestyle (35).

\section{Conclusion}

The results showed that patients, with the help of supportive resources available, try to overcome the difficulties that lie ahead and reduce the hemodialysisrelated stress. The use of supportive resources plays an important role in helping patients to return to normal and active life. Satisfaction with support resources (including family, medical personnel, similar patients, friends and community resources) makes the patient feel comfortable and accelerates returning to a normal life while the lack of such supportive resources leads to insecurity and tension in the patient and causes problems for the patient. Nurses' special attention to consequences of stress in patients undergoing hemodialysis seems to play an important role in providing a framework for appropriate supportive measures and gives the opportunity to nurses to manage the problems facing these patients.

\section{Limitation of the study}

This study is a limited qualitative study, therefore, the generalization of the results is limited and it is necessary to repeat the study in other places and with different cultural conditions.

\section{Conflicts of interest}

Authors declare no conflict of interest in the present study.

\section{Acknowledgements}

This article is part of a nursing doctoral thesis approved by the Shahid-Beheshti University with ethical code of IR.SBMU.PHNM.1394.198. The authors express their gratitude from participants, officials and staffs of hemodialysis wards, professors from other universities of medical sciences in Iran who participated in the confirmation of data extracted from interviews.

Authors' contribution

$\mathrm{MN}$ and MZ; conception, design, acquisition of data, data analysis, interpretation of data, literature review, drafting the article and final approval of manuscript. MI; critical revising for important intellectual content, design, final approval of manuscript. AK; drafting the article and final approval of manuscript.

\section{Ethical considerations}

Ethical issues (including plagiarism, data fabrication, double publication) have been completely observed by the authors.

\section{Funding/Support}

None.

\section{References}

1. Ribeiro R, Coutinho GL, Iuras A, Barbosa A, Camargo de Souza J, Diniz D, et al. Effect of resistance exercise intradialytic in renal patients chronic in hemodialysis. J Bras Nefrol. 2013;35:13-9. doi: 10.5935/01012800.20130003.

2. Mahdavi-Mazdeh M, Zamani M, Zamyadi M, Rajolani H, Tajbakhsh K, Heidary Rouchi A, et al. Hemodialysis cost in Tehran, Iran. Hemodial Int. 2008;12:492-8. doi: 10.1111/j.1542-4758.2008.00313.x.

3. Kaba E, Bellou P, Iordanou P, Andrea S, Kyritsi E, Gerogianni G, et al. Problems experienced by haemodialysis patients in Greece. Br J Nurs. 2007;16868-72. doi: 10.12968/ bjon.2007.16.14.24325.

4. Finnegan-John J, Thomas VJ. The psychosocial experience of patients with end-stage renal disease and its impact on quality of life: findings from a needs assessment to shape a service. ISRN Nephrol. 2013;2013:308986. doi: $10.5402 / 2013 / 308986$.

5. Turkmen K, Erdur FM, Guney I, Gaipov A, Turgut F, Altintepe L, et al. Sleep quality, depression, and quality of life in elderly hemodialysis patients. Int J Nephrol Renovasc. 2012;5:135-42. doi: 10.2147/IJNRD.S36493.

6. Longo D, Fauci A, Kasper D, Hauser S, Jameson J, Loscalzo J. Harrison Principles of Internal Medicine. New York, NY: McGraw Hill; 2012.

7. Sathvik BS, Parthasarathi G, Narahari MG, Gurudev KC. An assessment of the quality of life in hemodialysis patients using the WHOQOL-BREF questionnaire. Indian J Nephrol. 2008;18:141-9. doi: 10.4103/0971-4065.45288.

8. Tel H. Determining quality of life and sleep in hemodialysis patients. Nephrol Dial Transplant. 2009;38:210-5. doi: 10.1002/dat.20296.

9. Lazarus RS, Folkman S. Stress, Appraisal, and Coping. New York, NY: Springer; 1984.

10. Cohen S, Underwood LG, Gottlieb BH. Social support Measurement and Intervention: A Guide for Health and Social Scientists. New York: Oxford University Press; 2000.

11. Marshall GN, Davis LM, Sherbourne CD, Foy DW, Jaycox LH. A Review of the Scientific Literature As It Pertains to Gulf War Illnesses. Volume 4, Stress. DTIC Document; 1998.

12. Spektor DM. A Review of the Scientific Literature As It Pertains to Gulf War Illnesses. Volume 6. Oil Well Fires. DTIC Document; 1998.

13. Elo $\mathrm{S}$, Kyngas $\mathrm{H}$. The qualitative content analysis process. Aust J Adv Nurs. 2008;62:107-15. doi: 10.1111/j.13652648.2007.04569.

14. Krippendorff K. Content Analysis: An Introduction to Its 
Methodology. Thousand Oaks, CA: Sage; 2004.

15. Hsieh HF, Shannon SE. Three approaches to qualitative content analysis. Qual Health Res. 2005;15:1277-88. doi: $10.1177 / 1049732305276687$.

16. Speziale HS, Streubert HJ, Carpenter DR. Qualitative Research in Nursing: Advancing the Humanistic Imperative: Lippincott Williams \& Wilkins; 2011.

17. Vazquez I, Valderrabano F, Fort J, Jofre R, Lopez-Gomez JM, Moreno F, et al. Psychosocial factors and health-related quality of life in hemodialysis patients. Qual Life Res. 2005;14:179-90.

18. Harden J, Schafenacker A, Northouse L, Mood D, Smith D, Pienta K, et al. Couples' experiences with prostate cancer: focus group research. Oncol Nurs Forum. 2002;29:701-9.

19. Braun V, Clarke V. Using thematic analysis in psychology. Qual Res Psychol. 2006;3:77-101. doi: 10.1191/1478088706qp063oa.

20. Molazem Z, Ahmadi F, Mohammadi E, Bolandparvaz S. Nursing presence: essential element of caring of patients' perceptions. J Med Ethics Hist Med. 2010;3:44-54.

21. Welch JL, Austin JK. Stressors, coping and depression in haemodialysis patients. J Adv Nurs. 2001;33:200-7. doi: $10.1111 / j .1365-2648.2001 .01654 . x$.

22. Joshwa B, Khakha DC, Mahajan S. Fatigue and depression and sleep problems among hemodialysis patients in a tertiary care center. Saudi J Kidney Dis Transpl. 2012;23:72935. doi: 10.4103/1319-2442.98149.

23. Mashayekhi A, Abbaszade A, Rafiei H, Mashayekhi Sardoo $\mathrm{H}$, Borhani F. Effect of dignity therapy model on stress, anxiety and depression of hemodialysis patients. Int J Qual Health Care. 2015;1:28-31. doi: 10.5430/ijh.v1n1p28.

24. Bayat N, Alishiri GH, Salimzadeh A, Izadi M, Saleh DK, Lankarani MM, et al. Symptoms of anxiety and depression: A comparison among patients with different chronic conditions. J Res Med Sci. 2011;16:1441-7.

25. Diefenthaeler EC, Wagner MB, Poli-de-Figueiredo CE, Zimmermann PR, Saitovitch D. Is depression a risk factor for mortality in chronic hemodialysis patients? Rev Bras Psiquiatr. 2008;30:99-103. doi: 10.1590/S151644462011000400005.
26. Takaki J, Yano E. Possible gender differences in the relationships of self-efficacy and the internal locus of control with compliance in hemodialysis patients. Behav Med. 2006;32:5-11. doi: 10.3200/BMED.32.1.5-11.

27. Denhaerynck K, Manhaeve D, Dobbels F, Garzoni D, Nolte C, De Geest S. Prevalence and consequences of nonadherence to hemodialysis regimens. Am J Crit Care. 2007;16:222-35. doi: 10.3200/BMED.32.1.5-11.

28. Quinan P. Control and coping for individuals with end stage renal disease on hemodialysis: a position paper. CANNT J. 2007;17:77-84.

29. Cicolini G, Palma E, Simonetta C, Di Nicola M. Influence of family carers on haemodialyzed patients' adherence to dietary and fluid restrictions: an observational study. J Adv Nurs. 2012;68:2410-7. doi: 10.1111/j.13652648.2011.05935.x.

30. Kara B, Caglar K, Kilic S. Nonadherence with diet and fluid restrictions and perceived social support in patients receiving hemodialysis. J Nurs Scholarsh. 2007;39:243-8.

31. Kugler C, Vlaminck H, Haverich A, Maes B. Nonadherence with diet and fluid restrictions among adults having hemodialysis. J Nurs Scholarsh. 2005;37:25-9.

32. Brunner LS, Smeltzer SCC, Bare BG, Hinkle JL, Cheever KH. Brunner \& Suddarth's Textbook of Medical-Surgical Nursing. Lippincott Williams \& Wilkins; 2010.

33. Parsons TL, Toffelmire EB, King-VanVlack CE. Exercise training during hemodialysis improves dialysis efficacy and physical performance. Arch Phys Med Rehabil. 2006;87:680-7. doi: 10.1016/j.apmr.2005.12.044.

34. de Jonge P, Ruinemans GM, Huyse FJ, ter Wee PM. A simple risk score predicts poor quality of life and non-survival at 1 year follow-up in dialysis patients. Nephrol Dial Transplant. 2003;18:2622-8. doi: 10.1093/ndt/gfg453.

35. Chojak-Fijałka K, Smoleński O, Miłkowski A, Piotrowski W. The effects of 6-month physical training conducted during hemodialysis in ESRD patients. Arch Phys Med Rehabil. 2006;10:25-41. doi: 10.1155/2016/5672580.

Copyright $\odot 2017$ The Author(s); Published by Nickan Research Institute. This is an open-access article distributed under the terms of the Creative Commons Attribution License (http://creativecommons.org/licenses/by/4.0), which permits unrestricted use, distribution, and reproduction in any medium, provided the original work is properly cited. 